Original Research Paper

\title{
Pengenalan Irigasi Tetes Pada Anak- Anak Di Lingkungan Sekolah
}

\author{
I Dewa Gede Jaya Negara ${ }^{1 *}$, Anid Supriyadi ${ }^{1}$, I Gede Putu Warka ${ }^{1}$, I Wayan Yasa ${ }^{1}$, Salehudin ${ }^{1}$. \\ ${ }^{\text {I} P r o g r a m ~ S t u d i ~ T e k n i k ~ S i p i l, ~ F a k u l t a s T e k n i k, ~ U n i v e r s i t a s ~ M a t a r a m, ~ I n d o n e s i a ~}$
}

https://doi.org/10.29303/jpmpi.v3i2.929

Sitasi: Negara, I. D. G. J., Supriyadi, A., Warka, I. G. P., Yasa, I. W, \& Salehudin. (2021). Pengenalan Irigasi Tetes Pada Anak- Anak Di Lingkungan Sekolah. Jurnal Pengabdian Magister Pendidikan IPA, 4(3)

rticle history

Received: 22 Juli 2021

Revised: 31 Juli 2020

Accepted: 28 Agustus 2021

*Corresponding Author: I

Dewa Gede Jaya Negara

Program Studi Teknik Sipil,

FakultasTeknik, Universitas

Mataram, Mataram, Indonesia;

Email:

jayanegara@unram.ac.id

\begin{abstract}
Irigasi tetes merupakan sistem irigasi hemat air yang sudah lama diaplikasikan diberbagai negara, akan tetapi untuk di lingkungan diwilayah negara kita masih banyak yang belum mengenal. Memperhatikan adanya perubahan iklim global,yang berdampak pada ketersediaan air yang akan semakin menurun. Aplikasi irigasi tetes sangat mungkin dilakukan masyarakat, karena penggunaan airnya terbatas. Untuk itu pengenalan yang paling mungkin dilakukan adalah pada anak-anak sekolah, sebagai penerus bangsa. Pengabdian ini melakukan pelatihan irigasi tetes sebagai materi pengabdian yang dilakukan pada SMP Dwijendra Mataram. Sasaran pengabdian adalah semua anak-anak sekolah di sekolah SMP Dwijendra tersebut. Tujuan pelatihan ini adalah untuk menigkatkan pengetahuan dan ketarampilan siswa tentang irigasi tetes dan pertanian lahan terbatas. Pelatihan dilakukan dengan tahapan survey awal, ceramah di dalam kelas dan praktik irigasi tetes dihalaman sekolah. Hasil yang dicapai adalah siswa dan siswi SMP Dwijendra telah mendapatkan pengetahuan irigasi tetes, memahami dengan baik sistem irigasi tetes, mampu membuat jaringan irigasi dan mengatur jarak tanaman irigasi serta mampu mengoperasikan meningkat jaringan irigasi dan tanaman dengan baik..
\end{abstract}

Keywords: irigasi tetes, efisien, pertanian, terbatas

siswa yang ada, diharapkan dapat menerima pendidikan lebih khusus dan fokus sehingga kemampuan kompetensi anak dapat menjadi lebih baik.

Terbatasnya lahan-lahan di pekarangan perumahan dan mahalnya harga tanah, tidak diikuti oleh adanya peningkatan kreatifitas anak-anak didik dan warga sekolah dalam meningkatkan pengetahuannya pada usaha pertanian di lahan yang ada. Adanya lahan kosong di sekitar sekolah dapat dimanfaatkan untuk pengembangan pendidikan mandiri pada lingkungan sekolah. Terbatasnya sumber daya guru yang dapat memberikan pengetahuan tambahan berkaitan dengan pengetahuan pertanian, dapat membatasi kreatifitas guru dalam meningkatkan kompetensi anak didik, sehingga untuk itu perlu diberikan inovasi pada siswa dalam meningkatkan kemampuannya tentang teknik-teknik irigasi pada lahan terbatas untuk perumahan dan lainnya. Jadi melalui pemberian 
pembelajaran praktik pembuatan irigasi tetes dan jaringannya di halaman sekolah dalam waktu terbatas, siswa akan mendapatkan pengetahuan tambahan dan dapat membuat percobaan sendiri dan dapat meningkatkan pengetahuan.

Berdasarkan kondisi yang ada disekolah sasaran Sekolah Dwijendra rumusan masalah yang dapat diambil adalah bagaimana pemahaman irigasi tetes dapat diberikan ke siswa secara efektif, dan apakah siswa-siswi mampu menerima pembelajaran irigasi tetes dalam waktu yang terbatas. Apakah anak anak sekolah mau diberi pelajaran pembuatan irigasi tetes untuk mendukung usaha tani rumah tangga. Menurut Nakayama and Buck (1986) menyatakan bahwa tujuan utama dari pengairan tetes adalah untuk mensuplai air dan hara kepada tanaman dalam frekuensi tinggi dan volume rendah yang cukup untuk memenuhi kebutuhan kesuburan dan konsumtifnya.

Dari uraian latar belakang maka yang menjadi tujuan pengabdian ini adalah untuk meningkatkan pengetahuan dan keterampilan anakanak sekolah mulai tentang irigasi hemat air tetes yang sederhana

\section{Metode}

Upaya yang dilakukan agar kegiatan pengabdian pembelajaran irigasi tetes dapat dilakukan dengan efektif adalah dengan melakukan survey kondisi sasaran, penyiapan materi dan program pelatihan, pelaksanaan dan evaluasi pengabdian. Tim pelaksana pengabdian melakukan koordinasi dengan pengelola sekolah agar kegiatan dapat dilakukan dengan lancar dan siswa didik dapat dipersiapkan. Tahapan pelaksanaan kegiatan tersebut seperti berikut:

\section{Survey Lokasi}

Tim pelaksana melakukan survey awal ke sekolah Dwijendra Mataram untuk menggali permasalahan yang dapat dijadikan topik pembelajaran bagi anak-anak didik. Dalam kegiatan in tim mempelajari situasi sekolah dan pemondokan anak- anak seperti melihat aktifitasnya diluar jam sekolah, banyak yang bermain dan ada juga sebagian yang belajar, ada yang membersihkan halaman sekolah dan yang lainnya.Sedangkan situasi sekitar sekolah cukup asri dan luas, sehingga berpotensi dijadi lahan pertanian terbatas.

Memperhatikan masih banyaknya waktu luang anak- anak yang dapat dimanfaatkan untuk belajar, maka lahan yang masih kosong dapat dimanfaatkan untuk pembelajaran irigasi tetes dengan tanamannya.

\section{Waktu dan Tempat Pelaksanaan}

Waktu pelatihan hanya dapat dilakukan waktu hari minggu saat libur sekolah di sekolah SMP Dwijendra Mataram.

\section{Pelaksanaan Pelatihan}

Tahapan pelaksanaan terdiri dari pembelajaran di ruang kelas dan dilapangan. Pemecahan masalah awal dilakukan dengan peningkatkan pengetahuan dan pemahaman tentang sistem irigasi, pentingnya air bagi tanaman dan teknik irigasi tetes di ruang kelas.

Pada tahap berikutnya anak-nanak siswa dibimbing membuat jaringan irigasi tetes, menyiapkan air irigasi dan lahan tanam dengan polybag tanaman hortikultura. Dilakukan penataan jaringan di halaman sekitar sekolah sebagai sarana irigasi tanaman. Melalui pembuatan irigasi tetes, dapat memberi dampak positif pada perbaikan kesadaran dan peduli tentang manfaat lahan dan pentingnya berusahatani dilingkungan.

\section{Evaluasi dan Monitoring}

Kegiatan evaluasi dilakukan tim mulai dari awal kegiatan dilakukan sampai selesai pengabdian ini. Hal ini dilakukan untuk memastikan antosias peserta pengabdian dan menilai antosias dan peningkatan pemahaman selama kegiatan berjalan. Selama pelaksanaan kegiatan dilakukan tanya jawab dan diskusi dengan peserta pengabdian secara iteraktif.

\section{Hasil dan Pembahasan}

Kegiatan pengenalan tentang irigasi tetes untuk meningkatkan pengetahuan dilakukan didalam ruang kelas seperti yang tampak pada Gambar 1 di bawah ini. Pengenalan irigasi dilakukan di luar jam pelajaran siswa, sehingga dapat dihadiri oleh banyak siswa. Peserta tampak antusias mengikuti kegiatan yang merupakan materi pembuka bagi siswa yaitu materi baru karena belum pernah mereka di ajarkan dalam ruang kelas. 


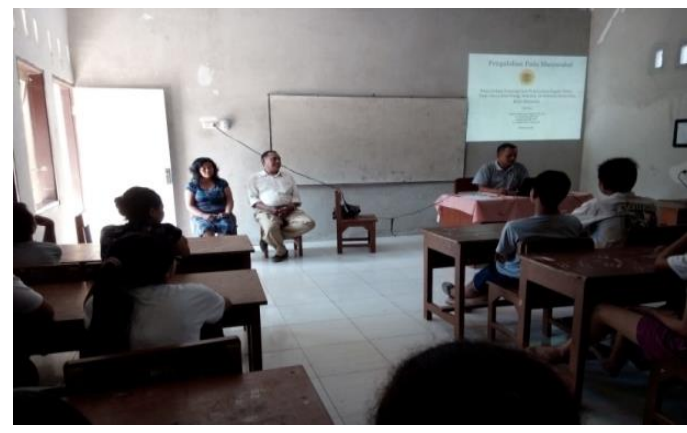

Gambar 1. Sosialisasi Irigasi Tetes di Ruang Kelas,Negara(2016)

Pengertian irigasi dan irigasi tetes disampaikan penyaji kepada siwa Dwijendra, dalam rangka mengenalkan sistem irigasi pada siswa. Dalam tahapan ini juga ditunjukkan contoh-contoh aplikasi lapangan sebagai penyegaran ilmu irigasi kepada siswa tersebut, yang selama ini sangat terbatas informasinya.

Pengairan tetes dicirikan oleh sifat-sifat berikut ini (Bucks and Davis, 1986): air dialirkan dengan kecepatan rendah pada periode waktu yang lama, dengan interval yang tinggi; air diberikan pada sekitar atau di dalam mintakat perakaran tanaman (root zone) melalui system pemberian bertekanan rendah.

Berdasarkan sumber yang diperoleh disampaikan bahwa, suatu pengairan tetes ideal adalah pengairan dimana semua emitternya mampu memberikan volume air dalam jumlah yang samapada pengairan tertentu sehingga setiap akan menerima jumlah air sama pada periode pengairan. Hal ini perlu disampaikan ke pada siswa-siwa pelajar agar difahami bahwa air irigasi perlu diberikan secara hemat dan sesuai kebutuhan tanaman.

Banyak sekali faktor yang berperan dalam ketepatan pemberian air , antara lain: sifat-sifat tanah dan faktor iklim. Tetapi komponen sistem yang paling kritikal dalam hal ini adalah emiternya (Warrick, 1986; Von Bernuth and Solomon, 1986).

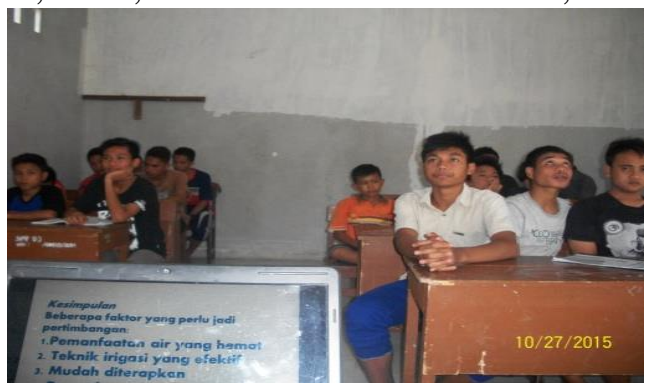

Gambar.2.Siwa Menyimak Paparan Materi, Negara (2016)
Inilah situasi peserta dalam menerima materi yang tampak bersemangat untuk ingin tahu tentang isi dari kegiatan ini. Materi secara garis besar merupakan pembekalan dalam membuat sistem irigasi tetes, yang mana pada tahap awal peserta harus mengenal istilah dan rupa dari sistem irigasi tersebut dan dapat mengetahui bagaimana sistem irigasi tersebut bekerja memberikan air pada tanaman. Selanjutnya setelah materi tersampaikan seluruhnya, maka tahapan berikutnya adalah memberikan kesempatan kepada peserta untuk bertanya bagi yang kurang mengerti.

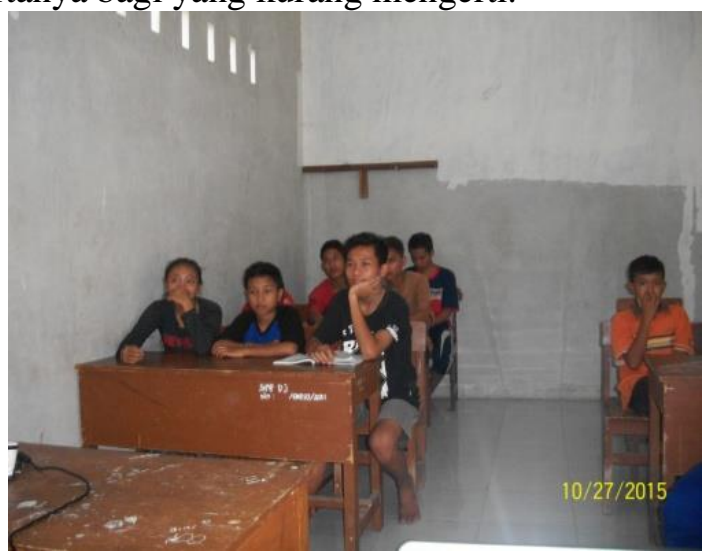

Gambar.3. Peserta Pelatihan di ruang kelas, Negara (2016)

Dalam sesi ini juga dilakukan tanya jawab dengan peserta. Pertanyaan peserta yang cukup banyak dan pertanyaan yang ada perlu di klasifikasikan lebih dulu, untuk memudahkan memberikan penjelasan atau jawaban. Pertanyaan-pertanyaan terdiri masalah bagaimana penerapnnya di lahan kering yang bergunung, jarak tanam dan ada juga yang menanyakan kenapa berbeda dengan cara irigasi di sawah sawah yang banyak airnya. Pertanyaan lain ada juga yang menanyakan bagaimana caranya membuat tampungan di daerah berbukit, agar air hujan dapat ditampung. Penyampaian tahapantahapan yang dilakukan dalam membuat jaringan irigasi tetes dengan pipa pvc dengan praktek langsung menggunakan media pelatihan.

Pembuatan Irigasi Tetes

Siswa diminta mengambil pipa pvc 1/2" untuk dilubangi dengan alat, kemudian mengambil sambungan pipa $\mathrm{T}$ dan $\mathrm{L}$ yang sudah di sediakan. Siswa diminta memperhatikan jarak tanam seperti tanaman terong, bagaimana menentukan jarak tersebut agar tanaman tetap tumbuh normal. 


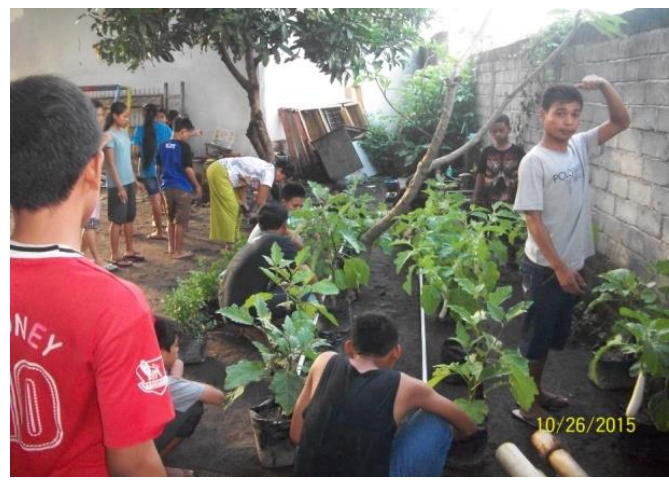

Gambar 4. Penyiapan Jaringan Irigasi (Negara, 2016)

Pamasangan jaringan irigasi dilakukan oleh siswa dan dipandu oleh tim pengadian. Jarak tanam ditentukan sesuai jenis tanaman yang ditanam, untuk tanaman tronh dipakai $70 \mathrm{~cm}$ karena daun dan dahannya lebat, untuk cabe dipakai jarak $60 \mathrm{~cm}$ minimal sedangkan untuk tanaman seladri digunakan jarak antara polybag $40 \mathrm{~cm}$. Dengan pengaturan jarak tanaman tersebut, diharapkan pertumbuhan tanaman tidak saling mengganggu sehingga memungkikan tanaman tumbuh dengan normal. Kegiatan tersebut ditunjukan pada Gambar 5 berikut.

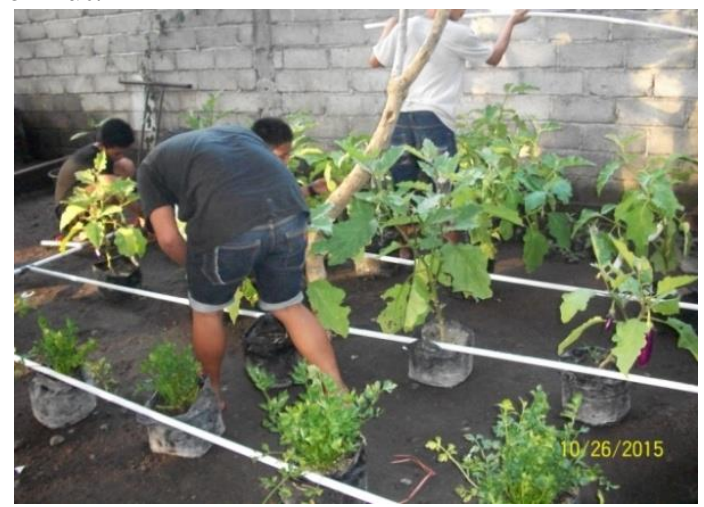

Gambar.5. Pengaturan jarak tanam (Negara, 2016)

Pengujian Irigasi Tetes

Setelah jaringan irigasi terpasang baik, tanam juga telah teratur jaraknya, secara langsung peserta diminta melakukan praktek langsung menggunakan jaringan irigasi tetes tersebut. Debit air dialirkan melalui selang ke jaringan tetes, kemudin aliran diatur menggunakan keran air sebagai pengatur aliran tetes seperti pada Gambar 6. Siswa diminta untuk memperhatikan bagaimana air bisa keluar dari lubang pipa tetes tersebut dan bagaimana mengaturnya agar air bisa keluar segaram pada tiap-tiap polybag.

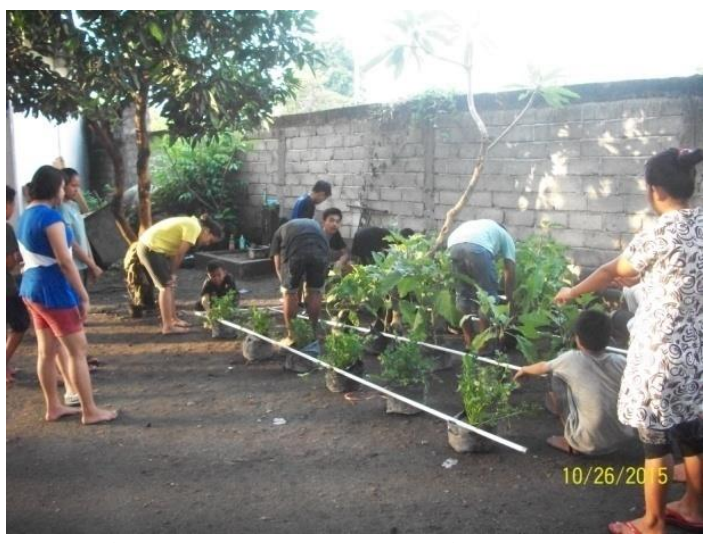

Gambar 6. Pengaturan Jarak Tanam Tetes

(Negara,2 016)

Siswa dibimbing dalam memasang gelas uji irigasi tetes, mengukur air yang tertampung dan membandingkan volume air yang ditampung dari masing-masing gelas penampung pada gelas ukur. melihat dan mengetahui langsung bagaimana caranya membuat irigasi tetes sederhana dan bagaimana caranya mengoperasikan. Dan dengan telah diperolehnya pengetahuan irigasi tetes, kemudian kegiatan tersebut sudah selesai dan siswa diminta untuk merawat dan memelihara anaman yang disumbangkan agar dapat memberi manfaat lanjutan.

Evaluasi dan diskusi diruangan kelas dilakukan setelah kegiatan pelatihan selesai dilakukan Gambar 7. Siswa diajak berdiskusi dengan pelaksanaan pelatihan tersebut, Tim mencatat masukan, kelemahan dan tingkat penyerapan materi oleh siswa tersebut.Kegiatan diskusi dilakukan secara kekeluargaan sehingga siswa tidak malu untuk bertanya ataupun dalam menjawab. Dengan cara ini diharapkan siswa mendapatkan tambahan wawasan dan pengetahuan baru tentang irigasi dan Bertani yang sederhana.

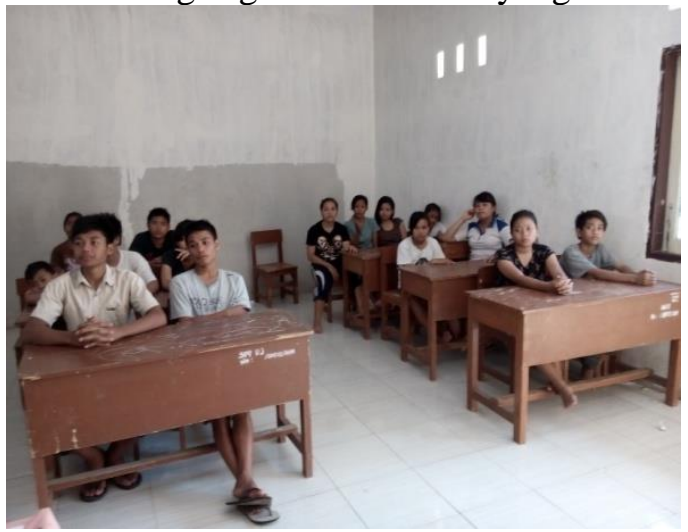

Gambar 7. Pertemuan di Ruang Kelas

(Negara, 2016) 


\section{Kesimpulan}

Adapun kesimpulan yang didapat dari pembahasan adalah:

1. Irigasi tetes dapat dimengerti oleh siswa dan siswi Dwijendra Mataram, dan sudah memperoleh pengetahuan tambahan tentang irigasi yang efisien dengan sistem tetes.

2. Selama pelaksanaan pelatihan siswa dan siswi dapat memahami tentang materi sistem irigasi tetes, dan sangat antusias saat dikenalkan dengan proses pembuatan irigasi tetes.

3. Disekolah pelajaran ekstrakurikuler peningkatan tentang usaha tani belum ada tapi untuk mata pelajaran ketahanan pangan sudah pernah diajarkan di sekolah.

4. Siwa dapat dengan mudah mengikuti pelatihan dan melakukan operasional sistem irigasi di lapangan praktek, dengan kondisi tersebut penyerapan siswa termasuk sangat bagus.

\section{Daftar Pustaka}

Bucks, D.A. and S. Davis, Historical development of trickle irrigation in Nakayama, F.S. and Bucks (ed), 1986. Trickle irrigation for crop production: Development in agricultural engineering 9. Elsevier, Amsterdam.

Bucks, D.A., F.S. Nakayama and A.W Warrick. Principles, practices and potentialities of trickle (drip) irrigation in Hillel, D. (ed), 1982. Advances in irrigation, vol. 1. Academic Press, New York.

Eterna dan Suwardji (2003). Survai pemanfaatan sumur pompa air tanah dalam se Pulau Lombok. Laporan Penelitian Kerjasama Bagian Proyek

Negara,I.D.G.J, Warka.I.G.P,dkk,( 2016),"Penyuluhan Tentang Cara Pembuatan Irigasi Tetes pada Siswa dan 